Julia Held

\title{
Die Anfechtung unentgeltlicher Leistungen gem. § 134 InsO
}

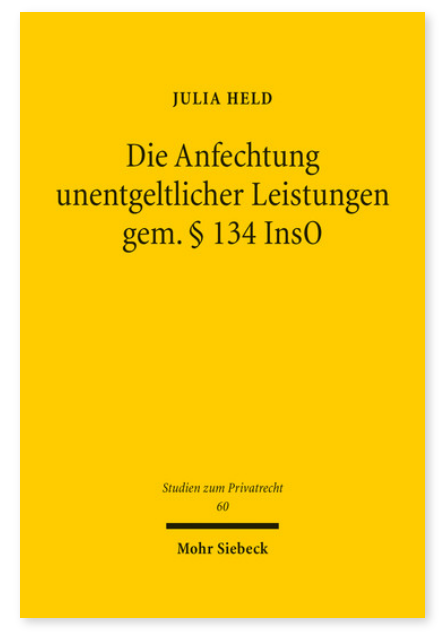

2017. XVIII, 549 Seiten. StudPriv 60

ISBN 978-3-16-154998-4

DOI 10.1628/978-3-16-154998-4

eBook PDF 139,00 €

ISBN 978-3-16-154997-7

Leinen $139,00 €$
Die Anfechtung unentgeltlicher Leistungen hat in den letzten Jahren eine Renaissance erfahren. Grund dafür ist die von Rechtsprechung und Literatur praktizierte, 'weite' Auslegung des § 134 InsO, die jedoch vor allem in Drei-PersonenVerhältnissen zunehmend auf Kritik stößt. Umso überraschender ist, dass es bislang an einer grundlegenden monographischen Auseinandersetzung mit der Unentgeltlichkeitsanfechtung fehlt. Diese Lücke schließt Julia Held mit der vorliegenden Arbeit. Sie erforscht umfassend die historischen und teleologischen Grundlagen der Unentgeltlichkeitsanfechtung und entwickelt davon ausgehend ein einheitliches Modell zur Auslegung des § 134 InsO. Neben dem Merkmal der Unentgeltlichkeit steht dabei insbesondere auch der Leistungsbegriff im Vordergrund, der die grundlegende Entscheidung darüber trifft, welche Zuwendungen der Einordnung in Entgeltlichkeit und Unentgeltlichkeit überhaupt zugänglich sind.

Julia Held Geboren 1987; Studium der Rechtswissenschaften in Heidelberg; 2011 Erste juristische Staatsprüfung; Wissenschaftliche Mitarbeiterin am Lehrstuhl für Bürgerliches Recht und Insolvenzrecht an der Ruprecht-Karls-Universität Heidelberg; 2016 Promotion; 2014-16 Rechtsreferendariat am Landgericht Mannheim.
Jetzt bestellen:

https://mohrsiebeck.com/buch/die-anfechtung-unentgeltlicher-leistungen-gem-134-inso-9783161549984?no_cache=1 order@mohrsiebeck.com

Telefon: +49 (0)7071-923-17

Telefax: +49(0)7071-51104 